\title{
IASPM D-A-CH: Current Issues and Perspectives $^{1}$
}

\author{
Beate Flath
}

Paderborn University

beate.flath@uni-paderborn.de

The German speaking branch of IASPM - IASPM D-A-CH (Germany, Austria and Switzerland) - was founded in 2013 in Bern, Switzerland. Since then, the number of members has steadily increased. At the moment, the branch represents around 170 members from various fields of popular music studies, e.g. universities, research networks, music industries, cultural policies, journalism, pop music, arts, etc.

Besides encouraging research on popular music in all its facets, one central concern of IASPM D-A-CH has been the long-term institutionalisation and integration of popular music studies in universities, conservatories, and academies as well as in funding agencies in Germany, Austria and Switzerland. To meet these aims, offers such as conferences and newsletters, etc., are supplemented by measures that support young scholars and expand publication opportunities. IASPM $\mathrm{D}-\mathrm{A}-\mathrm{CH}$ follows the motto of the "Five I-s" - international, interinstitutional, intergenerational, interdisciplinary and interprofessional - and acts as a link between German speaking and non-German speaking scholars, which is best represented by the large attendance of IASPM D-A-CH members at IASPM conferences (e.g. in Canberra in 2019).

The venue of the three-day biennial conference of IASPM D-A-CH alternates between Germany, Austria and Switzerland and is open to all scholars addressing the study of popular music. Following Bern, Siegen ("Conceptualizing Popular Music", organized by Cologne University of Music and Dance and the University of Siegen in 2014), Graz ("Darüber hinaus...Populäre Musik und überschreitung(en)" organised by the Karl-Franzens-University Graz in 2016) and again Bern ("Pop - Power - Positions. Global Relations and Popular Music", organised by the University of Bern and Bern University of the Arts in 2018), Paderborn University (Paderborn, Germany) will be the conference host in October 2020.

An essential part of every conference is the Maria Hanáček award, which has been given since 2013 for outstanding conference presentations by young scholars. This prize is awarded in memory of Maria Hanáček, one of the founding members

IASPM Journal vol.9 no.2 (2019) 
of IASPM D-A-CH who passed in 2013, and comes with 200 Euro. The Maria Hanáček award is presented by a seven-member jury, consisting of members of the executive committee, the advisory board as well as ordinary members of IASPM D-A-CH.

As already mentioned, supporting and promoting young scholars is an important concern of IASPM D-A-CH. As such, since 2015 young researchers have had the opportunity to attend the "Collegium Musicum Populare (CMP)" - an annual one or two-day workshop for scholars at the undergraduate and graduate levels. The CMP has been hosted by Goethe University Frankfurt (2015), University of Cologne (2016), University of Vienna (2018) and TU Braunschweig (2019). In 2020 the CMP will take place at the Humboldt-Universität, Berlin. The focus on critically reflecting and discussing research projects and their theoretical and methodological frameworks are accompanied by questions regarding career planning. These events provide an informal setting for open and respectful interactions, as well as opportunities for networking. Most importantly, they offer a low-threshold access point to the academic field while making the initiatives of IASPM and IASPM $\mathrm{D}-\mathrm{A}-\mathrm{CH}$ more visible to new generations of popular music scholars.

Besides supporting and promoting young scholars, our organization actively engages political issues. These include the politics of the academia and the recent rise of right-wing populism. Initiated by a number of members of IASPM D-A-CH during the biennial conference of 2018 in Bern, our experiences, needs and strategies were discussed and resulted in the founding of the $A G$ Populismus/Pop/Positionen ("Working committee Populism/Pop/ Positions"). This was followed by the installation of an internal mailing list and several offerings, such as workshops in Berlin, Oldenburg, Braunschweig and Vienna. One central outcome of these efforts is the resolution of the AG Populismus/Pop/Positionen, published on the 27th of September, 2019, by IASPM D-A-CH, GfPM - Gesellschaft für Popularmusikforschung ("German Society for Popular Music Studies") and GMM - Gesellschaft für Musikwirtschafts und Musikkulturforschung ("German Society for Music Business and Music Cultures Research"). The AG Populismus/Pop/Positionen aims to offer information, support and also a network to discuss experiences and strategies in meeting right-wing populism inside and outside academia. More information on this effort to address right-wing populism can be found on the website of IASPM D-A-CH. ${ }^{2}$

Another important innovation concerns the new publication platform of IASPM D-A-CH called " Vibes - The IASPM D-A-CH Series". This peer-reviewed online medium offers publication opportunities for conference presenters. The first volume collects contributions of the third IASPM D-A-CH conference in Bern (2018). Titled "Pop-Power-Positions. Global Relations and Popular Music", the volume is edited by Anja Brunner and Hannes Liechti and will be published in 2020. Supported by an international advisory board these series aim to show the wide range of topics, and the multiple theoretical and methodological frames utilized by German speaking popular music scholars. Future initiatives of IASPM D-A-CH will focus on establishing these concerns and activities in order to promote the further institutionalisation of popular music studies in all its approaches and facets.

\section{Endnotes}

(1) I would like to thank the executive committee of IASPM D-A-CH for providing additional information and data. 
(2) https://www.iaspm-dach.net/blog/2019/9/27/gemeinsame-resolution-gegen rechtspopulismus-kurzamplang-iaspm-d-a-ch-gfpm-und-gmm Accessed 3rd November 2019. 